\title{
PD-pulse characteristics in rotating machine insulation
}

\author{
Holbøll, Joachim; Henriksen, Mogens; Jensen, A; Sørensen, F.
}

Published in:

Conference Record of the IEEE International Symposium on Electrical Insulation

Link to article, DOI:

10.1109/ELINSL.1994.401502

Publication date:

1994

Document Version

Publisher's PDF, also known as Version of record

Link back to DTU Orbit

Citation (APA):

Holbøll, J., Henriksen, M., Jensen, A., \& Sørensen, F. (1994). PD-pulse characteristics in rotating machine insulation. In Conference Record of the IEEE International Symposium on Electrical Insulation (pp. 322-326). IEEE. https://doi.org/10.1109/ELINSL.1994.401502

\section{General rights}

Copyright and moral rights for the publications made accessible in the public portal are retained by the authors and/or other copyright owners and it is a condition of accessing publications that users recognise and abide by the legal requirements associated with these rights.

- Users may download and print one copy of any publication from the public portal for the purpose of private study or research.

- You may not further distribute the material or use it for any profit-making activity or commercial gain

- You may freely distribute the URL identifying the publication in the public portal

If you believe that this document breaches copyright please contact us providing details, and we will remove access to the work immediately and investigate your claim. 
Conference Record of the 1994 IEEE International Symposium on Electrical Insulation, Pittsburgh, PA USA, June 5-8, 1994

\section{PD-PULSE CHARACTERISTICS IN ROTATING MACHINE INSULATION}

\author{
J.T. Holbøll, M. Henriksen \\ Electric Power Engineering Dept. \\ Technical University of Denmark \\ Building 325, DK-2800 Lyngby \\ Denmark
}

\author{
A. Jensen \\ Asnæs Power Station \\ SK Power Company, Denmark \\ DK-4400 Kalundborg \\ Denmark
}

\author{
F. Sørensen \\ Project Division \\ SK Power Company, Denmark \\ Lautruphøj 5, DK-2750 Ballerup \\ Denmark
}

Abstract:

In this contribution will be presented results from investigations on partial discharges (PD) in insulation systems, resembling the stator insulation in high voltage rotating machines.

A model, simulating a stator winding in a slot, has been developed, consisting of simple rotating machine insulation test bars with epoxy/mica insulation, mounted between steel sheets forming a slot, in order to investigate the fundamental behaviour of PD in insulation defects in epoxy/mica insulation and the characteristics of the resulting electrical pulses.

Stator slot couplers (SSC) were used to detect pulses coming from artificial defects implemented in the model as well as from the existing voids in the test bars' insulation.

Some characteristic pulse shapes were found, which partly could be related to the defect type. The high frequency detection method, with directional couplers, made it possible to localize the defects thereby determining the pulse distortion in the chosen geometry. The influence of some parameters was investigated, such as the voltage applied, the location of the defect with respect to the sensor and the orientation of the defect in the slot. These informations are essential for PD-detection systems where the noise/signal separation is based on the pulse shape, such as the SSC-technology used in the present investigations.

\section{Introduction:}

Partial discharge (PD) detection in connection with high-voltage rotating machines gives the possibility of On-Line diagnostics on the insulation, since the most deteriorating phenomena, in the case of exposure to high electrical fields, will be accompanied by the occurrence of partial discharges. The high frequency character of the resulting PD-pulses, on one hand, makes it possible to separate these small signals from the large power frequency/harmonics signals, but, on the other hand, the measurements will be sensitive to internal as well as external high frequency noise.

As part of comparative investigations of several PD-detection systems for rotating machines, it was considered that knowledge of basic phenomena inside these machines would be necessary in order to be able to choose an appropriate system. This includes not only insight in the physical discharge process, but also the mechanisms of pulse transfer through the machine. Finally, the response of different detection systems to the detected signals has to be considered.

For that reason, an experimental approach has been made to simulate these phenomena and to determine the influence of some of the large number of parameters involved. In these initial investigations, different artificial voids were implemented at different locations in a simple model and the resulting electrical pulses detected at different voltages. This detection was done by Stator Slot Couplers (SSC), a sensor type that was considered to give the most detailed information, due to the close coupling between discharge and coupler.

\section{Artificial Voids in Epoxy/Mica Insulation}

Studies on the character of partial discharges in voids in electrical insulation need knowledge of void geometry, surface structure and gas content. In the case of rotating machine insulation, typical internal defects are delaminations between two layers of mica, poor contact between insulation and conductor, and voids due to poor impregnation under production. The nature of the gas inside these cavities will depend on the production process and the environment in the machine (air or hydrogen). In this study, only airfilled voids are considered.

As a first step towards well defined simulation of these defects, airfilled, cylindrical voids have been made, the one type with the void between two layers of epoxy/mica, the other type with metallic/dielectric boundaries. Both were made of mica paper (Romica) bonded to glass fiber backing and vacuum impregnated with an anhydride cured epoxy system (bisphenol-A diglycidylethers + methyl-nadic anhydride +accelerator).

The base material for the samples was $0.25 \mathrm{~mm}$ thick epoxy impregnated mica sheets, the surface of which was controlled under an optical microscope. As can be seen in Fig.1, the one surface was characterized by uncovered mica flakes embedded in the epoxy. The back surface consisted of clear epoxy only with the glass fibres visible just beneath the surface.

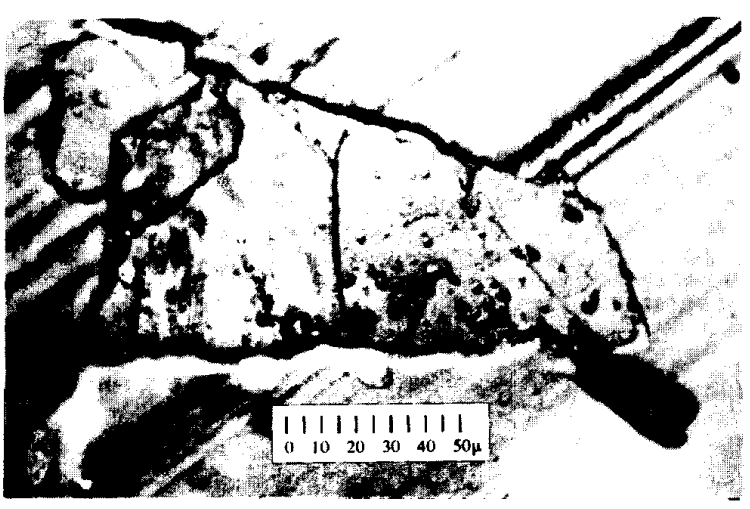

Fig.1 Typical surface structure of the epoxy impregnated mica tape with mica flakes protruding from the clear epoxy. The lines visible in the epoxy are caused by the surface of the mould.

The cylindrical void shape was obtained by placing three of the epoxy/mica sheets on top of each other, the middle sheet of which had a circular $5.5 \mathrm{~mm}$ hole punched. At this stage, the sheets only were pre-cured (B-stage), which made it possible for them to adhere during the final cure under high mechanical pressure. 
This procedure ensured good contact between the sheets, without any additional voids and without any adhesive affecting the geometry of the cavity. In order to ensure normal gas pressure inside the void, the sample was stored in air for 24 hours under normal conditions $\left(20^{\circ} \mathrm{C}, 1 \mathrm{bar}\right)$ after the final cure. Finally, the sample was cast into clear epoxy, hereby sealing the void and increasing the mechanical strength. The dimensions of the sample are shown in Fig.2.

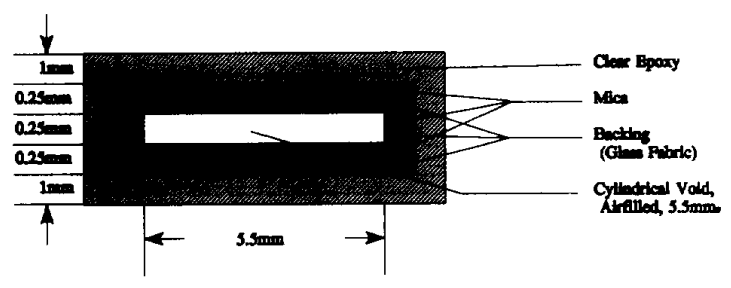

Fig.2 Cylindrical, airfilled void with dielectric/dielectric boundaries of epoxy/mica.

In Fig. 3 can be seen how the sample was embedded in the insulation of the test bars. This cast was made at room temperature with a soft epoxy type that made it possible, after the finished test, to remove the sample intact. Finally, the artificial defect was covered with a conductive graphite layer of app. $0.02 \mathrm{~mm}$ thickness.

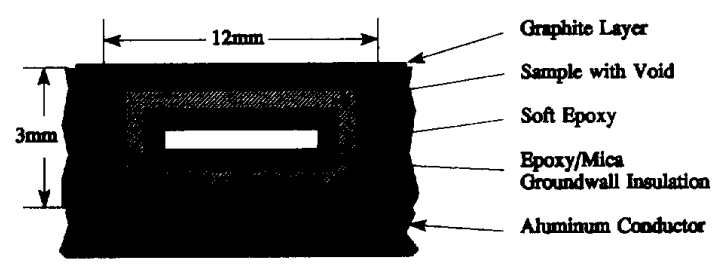

Fig.3 Cylindrical, airfilled void with dielectric/dielectricboundaries. Implemented in the test bar groundwall insulation.

The dielectric/metallic cylindrical void was made by glueing only two epoxy/mica sheets together in the same way as mentioned before, one sheet with a circular hole in the middle. This sample was placed directly on the conductor of the test bars with the opening facing the metal. After sealing and covering the defect with a conductive layer, a test configuration was achieved as shown in Fig.4

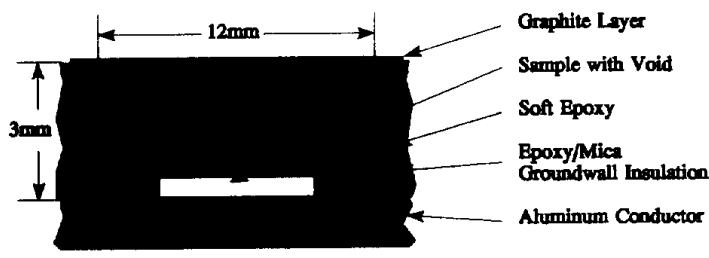

Fig.4 Cylindrical, airfilled void with dielectric/metallic boundaries. Implemented in the test bar groundwall insulation.

\section{Measuring Technique}

PD was measured with Stator Slot Couplers (SSC) that were placed directly onto the test bar. These couplers were ultrawide band antennas $(20-800 \mathrm{MHz})$, primarily developed for PD-detection on turbo-generators. They are normally placed under the stator wedges [1]. The stator slot acts as a transmission line which makes the high frequency response possible.

Due to two outputs, in the following named 'slot' and 'endwinding' directional measurements could be performed. Measuring of the time difference between the two made it possible to localize each discharge located between the two sensor ends. In the present investigations, using this capability of the SSC's, discharges, not originating from the artificial defect could be excluded.

Pulse shape measurements were performed by recording single shots with a 1Gigasampling/second digitizing oscilloscope, directly coupled to the SSC.

Measurements of the pulse distribution were made with a TGA pulse analyzer, manufactured by IRIS Power Engineering. By interpretating the pulse amplitude, width, phase position and time difference between the two SSC signals, the TGA normally classifies signals as being either PD or noise. This selection capability was not used under the present investigations, since all incoming pulses were caused by PD.

\section{Test Set-Up}

All tests were performed on $1.7 \mathrm{~m}$ long test bars, simulating the stator bar in high voltage rotating machines. As can be seen in Fig.5, these test bars consist of a $10 \times 50 \mathrm{~mm}$ aluminum conductor on top of which was applied a $3 \mathrm{~mm}$ vacuum impregnated epoxy/mica groundwall insulation covered with the usual semiconductive layer. At the slot end, a stress grading coating prevented surface discharges. The bars were laid down in a simulated stator slot, made of $5 \mathrm{~mm}$ steel, grounded properly and with close contact to the bar. At both ends, the conductor was extended by $1.7 \mathrm{~m}$ in order to minimize the influence of pulse reflections due to impedance discontinuities.

For the same reason, a defect location was chosen $40 \mathrm{~cm}$ from one of the slot ends. In order to determine the influence of the relative location of the SCC with respect to the defect, the sensor could be moved from a location at the slot end as shown in Fig.5, to a location just above the defect. The former position is the normal for SSCs, the latter made it certain to be able to determine the origin of the pulse detected.

The two types of defects were placed at the top of the bar (location A), at the side (location B) and orientated towards the slot bottom (location $\mathrm{C}$ ). The last was done by turning a bar with a defect in A upside down.

Before implementation of any defects, the test bars were PD-tested at different voltages. 


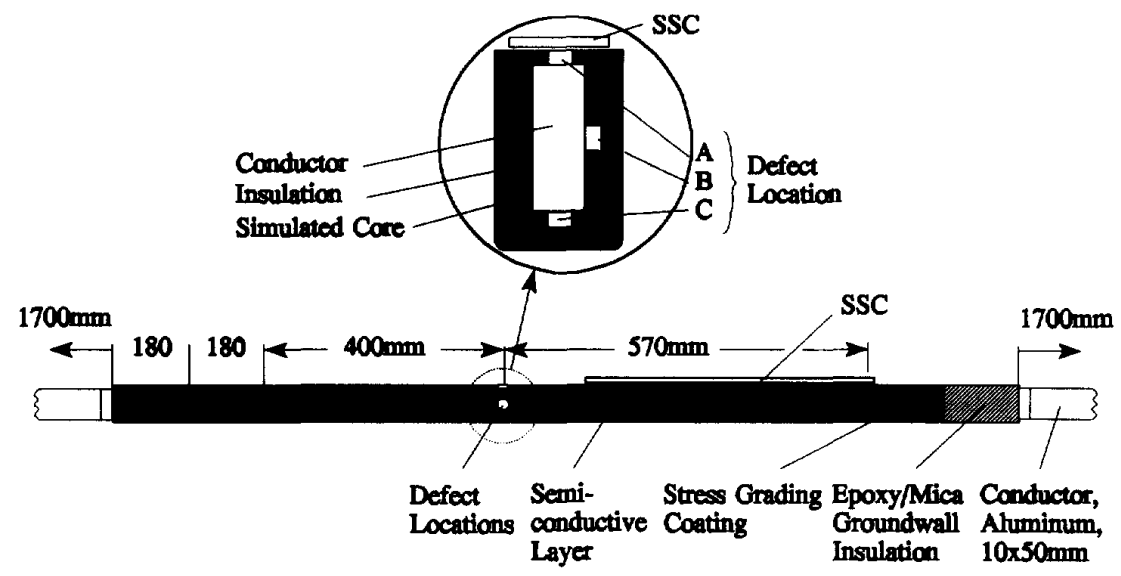

Fig.5 Test configuration. Epoxy/Mica insulated test bar with aluminum conductor placed in a simulated stator slot of $5 \mathrm{~mm}$ steel, defect and sensor locations.

\section{Results}

Test for PD on the test bars without an artificial defect showed a PD inception voltage between 5 and $6 \mathrm{kV}$ for the three bars used for the investigations.

The tests were made at four voltages: $4,5,6$ and $7 \mathrm{kV}_{\mathrm{rm}}$ to ground $50 \mathrm{~Hz}$. The voltage applied influenced the pulse height, but not the shape of the detected pulses. Therefore, the main purpose of using different voltage levels was to exclude PD from non-artificial voids. The measurements showed that for all defects, 4 and $5 \mathrm{kV}$ could be applied without starting any PD anywhere except in the implemented defect.

In order to stabilize the conditions inside the voids, voltage was applied for at least $30 \mathrm{~min}$ before any measurements were made.

As mentioned before, two types of defects (diel./diel. and diel./met.) were implemented at three different locations, and 4 voltages were applied. This test procedure resulted in large amounts of results which will only be presented in a summarized form in this paper.

\section{Detected Pulse Shapes}

Both types of defects were characterized by the occurrence of different pulse types, of which two very typical shapes are shown in Fig.6 (SSC located at slot end) and Fig.7 (SSC located above void).

In comparing the two pulse shapes, it can be seen that within the first 5 ns, the sharp initial pulses are almost identical, whereas the following 'tails' are quite different. These two pulse shapes were the most common, and for this pulse type, the initial similarity could be seen for pulses from all defects and at all SSC locations. The pulse height, however, varied, as will be shown later.

Other pulse types were found without the ringing as shown in Fig.6 and Fig.7. An example of these types is shown in Fig.8. Again, all defect types, at all locations, caused these 'slower' pulses, but with more sporadic occurrence.
An example of a third category of pulse shape can be seen in Fig.9. These types were especially seen in the diel./diel. void type. They occurred with either 2 or 3 peaks.

When increasing the test voltage to 6 and $7 \mathrm{kV}$, discharges started in the non-artificial defects. Pulses from these defects showed pulse shapes comparable to the ones from the cylindrical void. However, more detailed investigations on these discharges would be questionable, since only their location was known (determined by the SSC's), but not the defect geometry.

In some cases, pulse types of an oscillating character and with pulse widths of more than $15 \mathrm{~ns}$ were observed. By ultrasonic measurements, the origin of these was found to be poor electrical connection between a post insulator and the far end of the test bar $80 \mathrm{~cm}$ from the slot end.

\section{Pulse Distributions}

While the pulse shape is important when choosing an appropriate detection system, measurements of pulse distributions might give some informations about the character of the defect that has caused the discharges.

With the TGA, measurements of amplitude and amplitude/phase distributions of the incoming pulses were done.

Again, comparable results were obtained for all kinds of defects. An example of amplitude, as well as amplitude/phase distributions is shown in Fig. 10 and Fig.11

The expected asymmetry between numbers of positive and negative pulses could be observed in only few cases. An interesting observation was that pulses from PD in the same void located in A (towards wedges) and C (towards slot bottom) respectively, showed very little difference in the maximum amplitude.

Some decrease of discharge activity, with time, could be observed, an aging phenomena that will be studied in future investigations. 


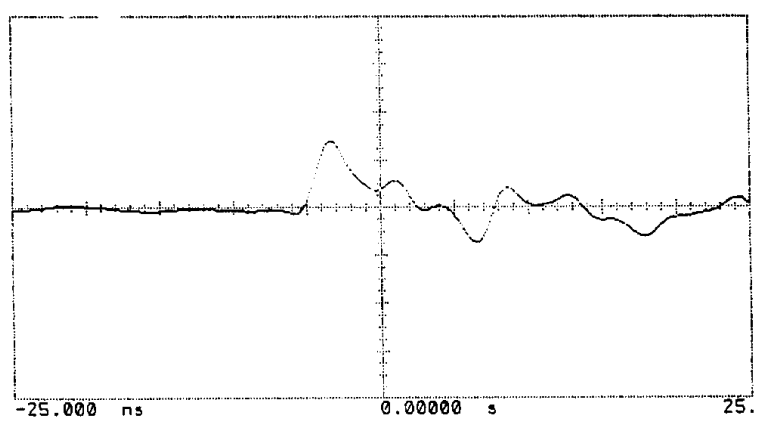

Fig.6 Typical pulse shape as seen from all types of defects. Diel./met. void located at A. SSC at slot end, output: slot. Test Voltage: $4 \mathrm{kV}$. X: $5 \mathrm{~ns} /$ div. $\mathrm{Y}: 50 \mathrm{mV} / \mathrm{div}$.

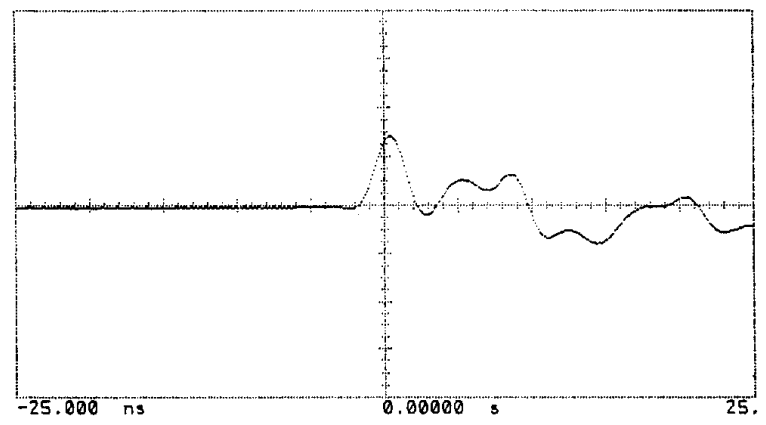

Fig.7 Typical pulse shape as seen from all types of defects. Diel./met. void located at A. SSC above void, output: slot. Test Voltage: $4 \mathrm{kV}$. X: $5 \mathrm{~ns} /$ div. Y: $50 \mathrm{mV} / \mathrm{div}$.

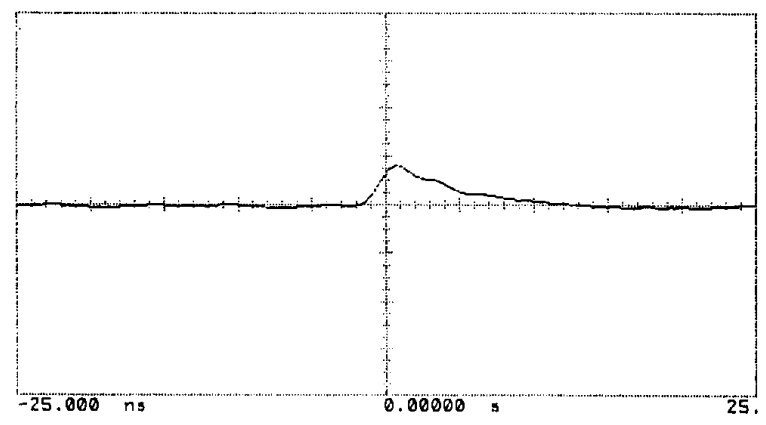

Fig.8 'Slow' pulse shape as seen from all types of defects. Diel./met. void located at B. SSC above void, output: slot. Test Voltage: $4 \mathrm{kV}$. X: $5 \mathrm{~ns} / \mathrm{div}$. Y: $20 \mathrm{mV} /$ div.

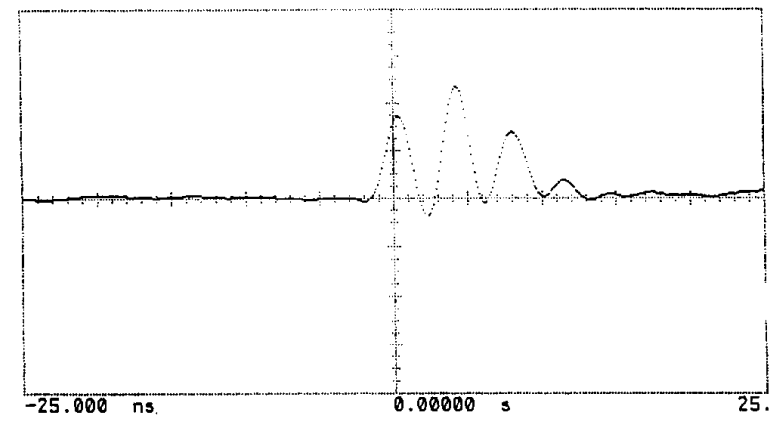

Fig.9 Example of 'multiple' pulses most seen in the diel./diel.void. Diel./diel. void located at A. SSC above void, output: slot. Test Voltage: $4 \mathrm{kV}$. X: 5ns/div. Y: $5 \mathrm{mV} /$ div.

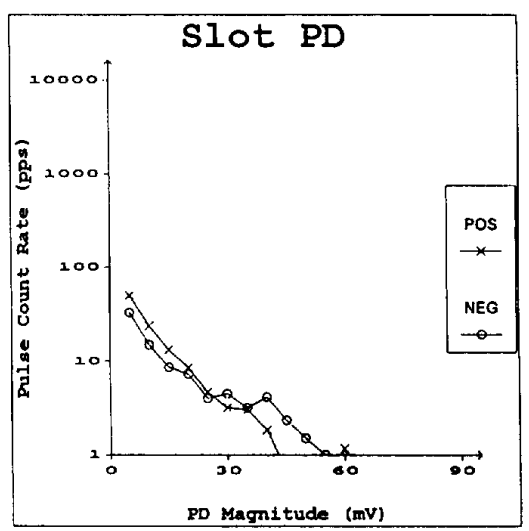

Fig.10 Typical amplitude distribution (TGA measured) Diel./met. void located at A. SSC at slot end. Test Voltage: $5 \mathrm{kV}$.

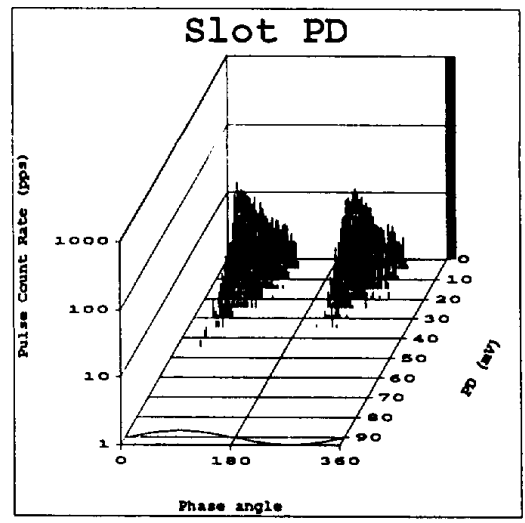

Fig.11 Typical amplitude/phase distribution (TGA measured) Diel./met. void located at A. SSC at slot end. Test Voltage: $5 \mathrm{kV}$. 


\section{Discussion:}

The occurrence of two different pulse types is recognized from PD in spherical voids. Earlier investigations [2] have shown that the occurrence of very fast pulses, as well as slower pulses, from PD in the same void under same conditions, is caused by two different discharge types.

The dependency of the pulse shape on the geometry was expected for two reasons: the impedance discontinuities, especially from the slot end, and in the high impedance endwinding, will cause pulse reflections interfering with the original pulse. Moreover, the detected pulse will always depend, not only the discharging process itself, but also on the configuration of all electrodes involved and the external circuit [3]. In many cases, the discharging process will be so fast, that the external circuit will determine the time variation of the measured pulse. This is probably the main reason for the almost identical shape of the major part of the discharges.

For the same reason, no measurements were made with a more simple electrode configuration. On the other hand, measurements with a simple 2-electrode system, with the void placed in between, could be useful for studies on the discharge process, and probably also for investigation of aging phenomena. With regard to evaluation of practical detection systems, however, a configuration, comparable to the one that can be expected in the field, should be used

Comparing the almost constant shape of most pulses (Fig.6) with former investigations showing very different pulse shapes caused by multiple discharges [4], it must be presumed that single discharges were the most dominating discharge type. The occurrence of multiple discharges also has been shown in flat cavities in low density polyethylene. A dependency on the cavity diameter/height ratio [5] was found, a fact that should be subject to more investigations, since delaminations - as a very common defect type in epoxy mica normally will have quite a high diameter/height ratio.

Two aspects have to be kept in mind with regard to high frequency PD-detection systems that register the pulse shape:

- The existence of at least two different pulse types caused by the discharge process itself under the same external conditions. This indicates different physical processes taking place in the void. Common for these pulse types was a pulse width of less than $10 \mathrm{~ns}$, even when the shape was affected by later coming reflections.

- The possibility of multiple discharges in flat cavities for which the time of occurrence between these single discharges is important. This is because pulses following very close to each other might cause pulse shapes normally not recognized as 'typical' PD-pulses.

If a pulse shape based detection system is desired for a specific machine, as a consequence of these findings, measurements of the actual pulse shape always should be made, before configurating the detection system.

As a result of these investigations, it was confirmed, that PD from the defect types used could be detected regardless of its orientation in the slot. The investigations have shown that the difference between PD-signals from a void placed on the top of the bar with the semiconductive layer as one electrode and signals from the same void placed between conductor and stator core is minimal.

The pulse distributions showed the expected pattern for dielectric/dielectric cavities, with the highest activity right after zero crossing. It was surprising that an asymmetrical pattern for PD did not exist for dielectric/metallic voids. This might be caused by an oxide layer or deteriorating products on the aluminum surface.

Pulse analyses might be useful in some cases, but the presen measurements have confirmed earlier findings, which showed that:

- asymmetrical phase/amplitude distributions indicate a metallic electrode involved in the discharge process, but
- symmetrical phase/amplitude distributions do not exclude the involvement of metallic electrodes [4].

The use of a solid material as simulated stator core might be discussed, since a laminated core will have a higher inductance than the $5 \mathrm{~mm}$ solid steel. Only PD originating from inside the slot was investigated. Endwinding discharges that might occur due to deteriorated stress grading coating or polluted endwindings, will be investigated later.

\section{Conclusion}

PD measurements were performed on discharges in flat, cylindrical cavities in epoxy/mica insulation, simulating delaminations inside the insulation and voids at the metallic conductor surface. PD from these defects implemented in a simulated stator winding, was detected by means of Stator Slot Couplers.

The investigations showed three types of pulse shapes, occurring under the same external conditions.

A fast type of constant shape, but varying amplitude, most likely caused by very fast single discharges in the cavity,

a slower pulse type, of different shapes and

multiple fast pulses, seen in the dielectric/dielectric void type.

All pulse types showed a pulse width less than 10ns, regardless of defect location or orientation. Pulse reflections from discontinuities, as the slot end, will interfere with the detected pulse, but do not affect the initial fast pulse.

Pulse analyses showed well known distributions, but without clear indications of the influence of the metallic surface involved.

These first tests seem to indicate that the SSC-technique gives very reliable results, with regard to identifying PD. The test system's capability of localizing defects made it possible to separate the signals from the artificial voids from signals coming from the non-artificial defects in the insulation.

Due to the sensors' high frequency response and the limited number of detected different pulse shapes, an identification procedure based on pulse shape seems to be reasonable. Ideally, all signals originating from PD should be classified as relevant. In order to determine the sensors' response to PD from other non-artificial defects such as surface discharging on the endwinding and slot discharges, further investigations need to be carried out.

\section{References}

[1] H.G.Sedding, S.R.Campbell, G.C.Stone, G.S.Klempner, "A New Sensor for Detecting Partial Discharges in Operating Turbine Generators", IEEE Transactions on Energy Conversion. Vol.6, No.4, December 1991, pp.700-706.

[2] J.T.Holbell, G.Stone, J.M.Braun, N.Fujimoto, "Temporal and Spatial Development of Partial Discharges in Spherical Voids in Epoxy Related to the Detected Electrical Signal." Annual Report of the Conference on Electrical Insulation and Dielectric Phenomena, Knoxville, USA, 1991, pp.581-588.

[3] A.Pedersen, G.C.Crichton, I.W.McAllister, "Partial Discharge Detection: Theoretical and Practical Aspects", Proceedings of the International Conference on Partial Discharges, Canterbury, UK, 1993, pp.21-24.

[4] J.T.Holbell, J.M.Braun, N.Fujimoto, G.C.Stone. "Partial Discharges in Flat, Dielectric/Metallic Bounded Cavities". Proceedings of the International Conference on Partial Discharges, Canterbury, UK, 1993, pp.39-40.

[5] P.H.F.Morshuis, "Partial Discharge Mechanisms", PhD thesis, Delft University Press, 1993, pp.39-40. 